\title{
Stochastic series lumped rainfall-runoff model for a watershed in Taiwan
}

\author{
Chi-Chun Lee ${ }^{\mathrm{a}, 1}$, Yih-Chi Tan ${ }^{\mathrm{b}, *}$, Chu-Hui Chen ${ }^{\mathrm{c}}$, T.-C. Jim Yeh ${ }^{\mathrm{d}}$ \\ ${ }^{a}$ Department of Architecture Historic Preservation, SHU-TE University, Kaohsiung County 824, Taiwan, ROC \\ ${ }^{\mathrm{b}}$ Department of Agricultural Engineering, Hydrotech Research Institute, National Taiwan University, Roosevelt Road, Taipei 106, Taiwan, \\ ROC \\ ${ }^{c}$ Department of Civil Engineering, China Junior College of Industrial and Commercial Management, Taipei 106, Taiwan, ROC \\ ${ }^{\mathrm{d}}$ Department of Hydrology and Water Resources, The University of Arizona, Tucson, AZ 87521, USA
}

Received 21 July 1999; revised 15 January 2001; accepted 6 February 2001

\begin{abstract}
The purpose of this paper is to develop a stochastic differential equation (SDE) for a lumped rainfall-runoff model and apply it to a watershed that consists of a number of subwatersheds in a series structure in Taiwan. Each subwatershed unit is treated as a two-part tank model. One part is for converting rainfall excess within the subwatershed into outflow at the subwatershed outlet. The other part converts subwatershed outflow into inflow at the next connecting subwatershed inlet. The measured values of rainfall excess are treated as random variables, and are used as input to the rainfall-runoff model. The development of the moment equations of simulated outflow is based on a SDE. The outflow hydrograph is obtained by applying the Laplace transform method to the equations that describe rainfall excess. (C) 2001 Elsevier Science B.V. All rights reserved.
\end{abstract}

Keywords: Stochastic differential equation; Rainfall-runoff model; Laplace transform; Unit-step function

\section{Introduction}

To improve the prediction of runoff that results from a causative storm, hydrologists need to consider the spatial and temporal variation of rainfall over the watershed. Ever since Sherman (1932) proposed the unit hydrograph concept, lumped rainfall-runoff models have been widely used to simulate the rainfall-runoff process of a watershed. One of the shortcomings of a lumped model for a runoff system

\footnotetext{
* Corresponding author. Fax: +8862-2363-9557. Present address SHU-TE University, Kaohsiung County 824, Taiwan, ROC.

E-mail address: yctan@ccms.ntu.edu.tw (Y-C.Tan).

${ }^{1}$ Present address: Department of Agricultural Engineering, National Taiwan University, Roosevelt Road, Taipei 106, Taiwan, ROC.
}

is its simplification of the spatial distribution of the rainfall excess input to the system. The input to the lumped model is taken to be a function of time only, and its value at any point is equal to the mean intensity over the watershed at any time. Wang and Chen (1996) suggested that a watershed should be treated as a system that consists of a number of subwatersheds, each of which is assumed uniform in terms of rainfall excess and geographic conditions. In their paper, several ordinary differential equations were assembled for subwatersheds that are connected in series or parallel, and these equations form a system of equations that apply to the entire watershed. The rainfall excess process of each subwatershed was represented by a unit-step function. The Laplace transform of rainfall excess was taken and substituted 
into the watershed system equation to obtain the Laplace transform of the outflow hydrograph of the watershed. The study by Wang and Chen (1996) is useful to introduce the preliminary concepts used in this paper.

The spatial and temporal variability of rainfall affects the accuracy of rainfall estimates over a watershed based on samples collected only at a few locations. Moreover, rain gauges may also often introduce significant errors in rainfall measurements. Environmental factors that control the rainfall-runoff process can vary spatially and temporally, and they may be uncertain as well. Subsequently, these uncertainties should be treated as stochastic processes and incorporated into modeling of watershed systems.

Stochastic methods have been used in combination with conceptual models since 1970. Early contributions (e.g. Moran, 1971; Quimpo, 1971, 1973; Weiss, 1973) focused on the development of conceptual models subject to stochastic inputs. Klemes (1974) obtained the probability distribution of outflows from a linear reservoir. Hjelmfelt and Bruwell (1984) provide a good case study of spatial and temporal variations of the effective rainfall over a catchment. Unny and Karmeshu (1984) approached this problem using stochastic differential equations (SDE). They treated parameters such as precipitation, evaporation, and the infiltration $(\Phi)$-index as stochastic. Bodo and Unny (1987) formulated a model that considered evaporation and precipitation as random inputs and also incorporated the relevant SDEs. Sarino and Serrano (1990) used simple watershed models, such as the Nash cascade of $n$ equal linear reservoirs, to investigate the effects of errors generated by the temporal variability of data. Hromodka II and Whitley (1994) used stochastic integral equations to investigate uncertainty in runoff due to the temporal uncertainty in rainfall distribution.

The uncertainty in runoff estimation can be modeled more accurately if the spatial variability of rainfall is considered. It is, therefore, desirable to develop a simple method that could be used to estimate watershed runoff by considering the spatial and temporal variability of rainfall. Accordingly, the objective of the present article is to develop a simple method to derive and analyze a direct runoff hydrograph as a random function. We develop and solve the SDE that governs the random direct runoff hydrograph. The SDE is specifically formulated for a watershed that can be treated as a system of subwatersheds in series, and the entire methodology is subsequently applied to the Shihmen Reservoir watershed in Taiwan.

\section{Development of a series lumped rainfall-runoff model}

A watershed can be divided into $n$ subwatersheds in series according to geographical properties. For each subwatershed, the mass balance equation is

$$
\frac{\mathrm{d} S}{\mathrm{~d} t}=I-Q
$$

where $S(\mathrm{~mm})$ is the storage of a subwatershed, $I(\mathrm{~mm} / \mathrm{h})$ the input to the subwatershed, and $Q(\mathrm{~mm} / \mathrm{h})$ is the output from the subwatershed. The storage-release equation is assumed to be

$S=K Q$

where $K(\mathrm{~h})$ is the storage constant of the watershed. Substituting Eq. (2) into Eq. (1) leads to

$$
\frac{\mathrm{d} Q}{\mathrm{~d} t}=\frac{1}{K}(I-Q)
$$

Using the control area of stream flow stations (the stream flow stations are located at the outlet of watersheds) as a guide, the area of the watershed is divided into $n$ subwatersheds. The storage-release equations for the $n$ subwatersheds are

$\frac{\mathrm{d} Q_{i}}{\mathrm{~d} t}=\frac{1}{K_{i}}\left(I_{i}-Q_{i}\right), \quad i=1 \ldots n$

The input of the first subwatershed is the rainfall excess, $P_{1}$, only, which represents the amount of rainfall after infiltration. For the down-gradient subwatersheds, the input will be the rainfall excess, $P_{i}$, plus the direct runoff, $Q_{i}$, from the upstream subwatershed. For $n$ subwatersheds, the input can be written mathematically as

$I_{i}=P_{i}+Q_{i-1}, \quad i=1, \ldots, n, Q_{0}=0$

When Eq. (5) is substituted into Eq. (4), we obtain the following:

$\frac{\mathrm{d} Q_{i}}{\mathrm{~d} t}=\frac{1}{K_{i}}\left(P_{i}+Q_{i-1}-Q_{i}\right), \quad i=1, \ldots, n Q_{0}=0$ 
Eq. (6) represents a series lumped rainfall-runoff model of a watershed.

\section{Stochastic differential equation}

The rainfall excess input to a model always has some degree of uncertainty because of the temporal and spatial variability of rainfall, infiltration, and measurement errors. Accordingly, the rainfall excess of each subwatershed is expressed as follows:

$P_{i}=\bar{P}_{i}+P_{i}^{\prime}, \quad i=1, \ldots, n$

where $\bar{P}_{i}$ represents the deterministic components, which may be time-dependent, and $P_{i}^{\prime}$ represents the fluctuating components. Substituting Eq. (7) into Eq. (6) yields

$\frac{\mathrm{d} Q_{i}}{\mathrm{~d} t}=\frac{1}{K_{i}}\left(\bar{P}_{i}+Q_{i-1}-Q_{i}\right)+\frac{P_{i}^{\prime}}{K_{i}}$,

$i=1, \ldots, n, Q_{0}=0$

The stochastic components are assumed white-noise Gaussian processes with zero means and a deltacorrelated structure as described by Unny (1984)

$E[W(t)]=0$

$E\left[W(t) W^{\mathrm{T}}(t-\tau)\right]=D \delta(\tau)$

where $W(t)=\left[P_{1}^{\prime}, \ldots, P_{n}^{\prime}\right]^{\mathrm{T}}, \delta(\tau)$ is the Dirac delta function and $D=\operatorname{diag}\left[\sigma_{P_{1}^{\prime}}^{2}, \ldots, \sigma_{P_{n}^{\prime}}^{2}\right]$ in which the squared terms $\sigma_{P_{1}^{\prime}}^{2}, \ldots, \sigma_{P_{n}^{\prime}}^{2}$ represent the variances of $P_{1}^{\prime}, \ldots, P_{n}^{\prime}$.

As the white Gaussian process is not an ordinary function of time $t$, the second term on the right side of the stochastic differential of Eq. (8) is not mean square Riemann integrable. However, the white Gaussian process can be described as the formal derivative in time of a Brownian motion process $B$ with independent increments $\mathrm{d} B$ in time $\mathrm{d} t$ characterized by

$E[\mathrm{~d} B(t)]=[0]$

$E\left[\mathrm{~d} B(t) \mathrm{d} B^{\mathrm{T}}(t)\right]=\vec{D} \mathrm{~d} t$

$\mathrm{d} B^{\mathrm{T}}(t)=W^{\mathrm{T}}(t) \mathrm{d} t=\left[P_{1}^{\prime}, \ldots, P_{n}^{\prime}\right] \mathrm{d} t$

Thus, Eq. (8) can be rewritten as

$\mathrm{d} Q=F(Q, t) \mathrm{d} t+G(Q, t) \mathrm{d} B(t)$ where $\quad \mathrm{d} Q=\left[\mathrm{d} Q_{1}, \ldots, \mathrm{d} Q_{n}\right]^{\mathrm{T}}, \quad F(Q, t)=\left[\left(\bar{P}_{1}-\right.\right.$ $\left.\left.Q_{1}\right) / K_{1}, \ldots,\left(\bar{P}_{n}+Q_{n-1}-Q_{n}\right) / K_{n}\right]^{\mathrm{T}}, \quad G(Q, t)=$ $\operatorname{diag}\left[1 / K_{1}, \ldots, 1 / K_{n}\right]^{\mathrm{T}}, \quad \mathrm{d} B(t)=\left[P_{1}^{\prime}, \ldots, P_{n}^{\prime}\right]^{\mathrm{T}} \mathrm{d} t$.Eq. (14) is a stochastic different equation and its solution, $Q(t)$, is a time-dependent Markov diffusion process. Subsequently, $Q(t)$ is fully determined if the join probability density function of the random variable $Q(t)$ is defined for all finite sets of $t$. This is, however, a very ambitious goal, which is difficult to achieve in most cases. In practice, it is satisfactory if a limited number of moments of the solution process are derived. The most significant moments are the first and second moments, which are the subjects of the following analysis.

\section{The moment equations}

Considering a real function $\phi(Q(t), t)$ Soong (1973) determined that

$\phi(Q(t), t)=\prod_{i=1}^{n} Q_{i}^{a_{i}}(t)$

and

$\sum_{i=1}^{n} a_{i}=m$

where $a_{i}$ is a constant, $m$ the level of the moment, and $n$ is the number of variables. Consider an arbitrary function $\phi(Q(t), t)$ of $Q(t)$ and $t$, whose partial derivatives $\partial^{2} \phi / \partial Q_{i} \partial Q_{j}$ and $\partial \phi / \partial t$ are continuous and bounded over any finite interval of $Q(t)$ and $t$. If we use $\delta$ as a finite forward increment operator over the time increment $\delta t$, we have

$\delta \phi(Q, t)=\phi(Q+\delta Q, t+\delta t)-\phi(Q, t)$

The Taylor series expansion of $\delta h$ then gives

$$
\begin{aligned}
\delta \phi= & \sum_{j=1}^{n} \delta Q_{j} \frac{\partial \phi}{\partial Q_{j}}+\frac{1}{2} \sum_{i, j=1}^{n} \delta Q_{i} \delta Q_{j} \frac{\partial^{2} \phi}{\partial Q_{i} \partial Q_{j}}+\delta t \frac{\partial \phi}{\partial t} \\
& +\mathrm{o}\left(\delta Q \delta Q^{\mathrm{T}}\right)+\mathrm{o}(\delta t)
\end{aligned}
$$

Referring back to the general equation (14), we have shown that

$$
E\left[\delta Q_{j}(t) \mid Q\right]=F_{j}(Q, t) \delta t+\mathrm{o}(\delta t)
$$


$E\left[\delta Q_{i}(t) \delta Q_{j}(t) \mid Q\right]=2\left(G D G^{\mathrm{T}}\right)_{i j} \delta t+\mathrm{o}(\delta t)$

Substituting Eqs. (18) and (19) into Eq. (17) and taking the conditional expectation of Eq. (17) yields

$E[\delta \phi \mid Q]$

$$
\begin{aligned}
= & \sum_{j=1}^{n} F_{j}(Q, t)\left(\frac{\partial \phi}{\partial Q_{j}}\right) \delta t \\
& +\sum_{i, j=1}^{n}\left(G D G^{\mathrm{T}}\right)_{i j} \frac{\partial^{2} \phi}{\partial Q_{i} \partial Q_{j}} \delta t+\frac{\partial \phi}{\partial t} \delta t+\mathrm{o}(\delta t)
\end{aligned}
$$

The expectation $E[\delta \phi \mid Q]$ is regarded here as a random variable. In view of the above, the expectation of Eq. (20) gives

$$
\begin{aligned}
& E[\delta \phi]=E[E[\delta \phi \mid Q]] \\
& =\sum_{j=1}^{n} E\left[F_{j}(Q, t) \frac{\partial \phi}{\partial Q_{j}}\right] \delta t \\
& \quad+\sum_{i, j=1}^{n} E\left[\left(G D G^{\mathrm{T}}\right)_{i j}\left(\frac{\partial^{2} \phi}{\partial Q_{i} \partial Q_{j}}\right)\right] \delta t+E\left[\frac{\partial \phi}{\partial t}\right] \delta t \\
& \quad+\mathrm{o}(\delta t)
\end{aligned}
$$

Finally, upon dividing Eq. (21) by $\delta t$, and taking the limit when $\delta t \rightarrow 0$, we obtain the following ordinary differential equation:

$$
\begin{aligned}
\frac{\mathrm{d} E[\phi]}{\mathrm{d} t}= & \sum_{j=1}^{n} E\left[F_{j} \frac{\partial \phi}{\partial Q_{j}}\right] \\
& +\sum_{i, j=1}^{n} E\left[\left(G D G^{\mathrm{T}}\right)_{i j} \frac{\partial^{2} \phi}{\partial Q_{i} \partial Q_{j}}\right]+E\left[\frac{\partial \phi}{\partial t}\right]
\end{aligned}
$$

If we substitute Eq. (15) into Eq. (22), the latter becomes the moment equation for $E\left\{\prod_{i=1}^{n} Q^{a_{i}}(t)\right\}$.

\section{The solutions of moment equation}

If the model parameters of subwatersheds are the same (i.e. $K_{1}=K_{2}=\cdots=K_{n}=K$ ), then the first moment can be obtained from Eq. (15)

$\sum_{i=1}^{n} a_{i}=1, \quad a_{1}+a_{2}+\cdots+a_{n}=1$,

$\phi(Q(t), t)=Q_{1}^{a_{1}} Q_{2}^{a_{2}} \cdots Q_{n}^{a_{n}}$

We let $a_{1}=1, a_{2}=\cdots=a_{n}=0$ and $\phi(Q(t), t)=$ $Q_{1}$, substitute these into Eq. (22), and we have the first moment of $Q(t)$ for the first subwatershed

$E\left[Q_{1}\right]=\frac{\bar{P}_{1}}{K(D+1 / K)}$

where $D$ is the differential operator $\mathrm{d}(\mathrm{)}) \mathrm{d} t$. Similarly, the first moment of other subwatersheds can be written as

$E\left[Q_{n}\right]=\sum_{j=1}^{n} \frac{\bar{P}_{n-j+1}}{K^{j}(D+1 / K)^{j}}$

The second moments of the runoff in the watersheds 1 and 2 are given as

$$
E\left[Q_{1}^{2}\right]=\frac{2 \bar{P}_{1}^{2}}{K^{2}(D+2 / K)(D+1 / K)}+\frac{2 \sigma_{P_{1}^{\prime}}^{2}}{K^{2}(D+2 / K)}
$$

$$
\begin{aligned}
E\left[Q_{2}^{2}\right]= & {\left[\frac{2}{(D+2 / K)^{3}(D+1 / K)}\right.} \\
& \left.+\frac{1}{(D+2 / K)^{2}(D+1 / K)^{2}}\right] \frac{2 \bar{P}_{1}^{2}}{K^{4}} \\
& +\left[\frac{2}{(D+2 / K)^{2}(D+1 / K)}\right. \\
& \left.+\frac{1}{(D+2 / K)(D+1 / K)^{2}}\right] \frac{2 \bar{P}_{1} \bar{P}_{2}}{K^{3}} \\
& +\left[\frac{1}{(D+2 / K)(D+1 / K)}\right] \frac{2 \bar{P}_{2}^{2}}{K^{2}} \\
& +\left[\frac{1}{(D+2 / K)^{3}}\right] \frac{4 \sigma_{P_{1}^{\prime}}^{2}}{K^{4}} \\
& +\left[\frac{1}{(D+2 / K)}\right] \frac{2 \sigma_{P_{2}^{\prime}}^{2}}{K^{2}}
\end{aligned}
$$


The general form of the second moment for $n$th watershed can be expressed as

$$
\begin{aligned}
& E\left[Q_{n}^{2}\right]=\sum_{s=1}^{n} \sum_{x=0}^{n-x} \frac{2 \bar{P}_{s} \bar{P}_{x+s}}{K^{2(n-s+1)-x}} \\
& \times\left[\sum_{w=1}^{n-s+1} \frac{1}{(D+2 / K)^{2(n-s+1)-w-x}(D+1 / K)^{w}} Z_{n s x w}\right] \\
& +\sum_{y=1}^{n}\left[\frac{1}{(D+2 / K)^{(2 y-1)}}\right] \frac{2 R_{n y} \sigma_{P_{n-y+1}}^{2}}{K^{2 y}}
\end{aligned}
$$

where $Z_{n s x w}$ and $R_{n y}$ are constants, varying with $n$. When $n=1, \quad Z_{1101}=1, \quad R_{11}=1 ;$ when $n=2$, $Z_{2101}=2, Z_{2102}=1, Z_{2111}=2, Z_{2112}=1, Z_{2201}=$ $1, R_{21}=1, R_{22}=2$; when $n=3, Z_{3101}=6, Z_{3102}=$ $3, Z_{3103}=1, Z_{3111}=6$, and so on.

$\bar{P}_{1}, \bar{P}_{2}, \ldots, \bar{P}_{n}$ are the spatial averages of rainfall excess of the each subwatershed. In reality, the rainfall process is a continuous time function and is difficult to know with certainty. The rainfall excess is represented by a unit-step function in this paper. Heaviside (1971) proposed the unit-step function concept. Its definition is

$U(t-a)= \begin{cases}0 & t \leq a \\ 1 & t>a\end{cases}$

The Laplace transform of the unit-step function is given by

$L[U(t-a)]=\frac{\exp (-a s)}{s}$

According to the unit-step function concept, continuous rainfall excess can be expressed in blocks of equal duration and the value of each block is the average of the continuous rainfall excess over the block. Therefore, the rainfall excess distribution can be expressed as

$$
\begin{gathered}
\bar{P}_{j}(t)=\bar{p}_{0 j} U(t)+\left(\bar{p}_{1 j}-\bar{p}_{0 j}\right) U(t-\Delta t)+\ldots \\
\quad+\left(\bar{p}_{m j}-\bar{p}_{(m-1) j}\right) U(t-m \Delta t)-\bar{p}_{m j} U(t-(m+1)) \\
\Delta t=\sum_{i=0}^{m+1} C_{i j} U(t-\mathrm{i} \Delta t), \quad j=1 \ldots n
\end{gathered}
$$

where $n$ is the number of subwatersheds and $m$ is the number of time intervals, $C_{0 n}=\bar{p}_{0 n}, C_{1 n}=$ $\bar{p}_{1 n}-\bar{p}_{0 n}, \ldots, C_{m n}=\bar{p}_{m n}-\bar{p}_{(m-1) n}, C_{(m+1) n}=-\bar{p}_{m n}$, $\bar{p}_{0 n}, \bar{p}_{1 n}, \ldots, \bar{p}_{(m-1) n}, \bar{p}_{m n}$ are the average rainfall excess of each time interval of subwatershed $n$.

Substituting Eq. (30) into Eq. (24) and conducting a Laplace transform for Eq. (24), we obtain

$$
\begin{aligned}
& E\left[Q_{1}(t)\right]=\sum_{i=0}^{m+1} C_{i 1} U(t-\mathrm{i} \Delta t)\left[1-\mathrm{e}^{-(1 / K)(t-\mathrm{i} \Delta t)}\right] \\
& E\left[Q_{2}(t)\right]=\sum_{i=0}^{m+1} C_{i 2} U(t-\mathrm{i} \Delta t)\left[1-\mathrm{e}^{-(1 / K)(t-\mathrm{i} \Delta t)}\right] \\
& +\sum_{i=0}^{m+1} C_{i 1} U(t-\mathrm{i} \Delta t) \\
& \quad \times\left[1-\mathrm{e}^{-(1 / K)(t-\mathrm{i} \Delta t)}-\frac{(t-\mathrm{i} \Delta t)}{K} \mathrm{e}^{-(1 / K)(t-\mathrm{i} \Delta t)}\right]
\end{aligned}
$$

$$
\begin{aligned}
& E\left[Q_{n}(t)\right]=\sum_{j=1}^{n} \sum_{i=0}^{m+1} C_{i(n-j+1)} U(t-\mathrm{i} \Delta t) \\
& \times\left[1-\sum_{w=0}^{j-1}(w !)^{-1}\left(\frac{t-\mathrm{i} \Delta t}{K}\right)^{w} \mathrm{e}^{-(1 / K)(t-\mathrm{i} \Delta t)}\right]
\end{aligned}
$$

Similarly, the second moment of the output of subwatersheds with the same parameter $K$ also can be obtained by the Laplace transform method to yield the following:

$$
\begin{aligned}
& E\left[Q_{1}^{2}(t)\right]=\sum_{i=0}^{m+1} C_{i 1} \sum_{i=0}^{m+1} C_{i 1} U(t-\mathrm{i} \Delta t) \\
& \quad \times\left[1-2 \mathrm{e}^{-(1 / K)(t-\mathrm{i} \Delta t)}+\mathrm{e}^{-(2 / K)(t-\mathrm{i} \Delta t)}\right]+\frac{\sigma_{P_{1}^{\prime}}^{2}}{K} \\
& \quad \times\left[1-\mathrm{e}^{-(2 / K) t}\right]
\end{aligned}
$$




$$
\begin{aligned}
& E\left[Q_{2}^{2}(t)\right]=\sum_{i=0}^{m+1} C_{i 1} \sum_{i=0}^{m+1} C_{i 1} U(t-\mathrm{i} \Delta t)\left[1-2 \mathrm{e}^{-(1 / K)(t-\mathrm{i} \Delta t)}-2 \frac{(t-\mathrm{i} \Delta t)}{K} \mathrm{e}^{-(1 / K)(t-\mathrm{i} \Delta t)}+\mathrm{e}^{-(2 / K)(t-\mathrm{i} \Delta t)}\right] \\
& +\sum_{i=0}^{m+1} C_{i 1} \sum_{i=0}^{m+1} C_{i 1} U(t-\mathrm{i} \Delta t)\left[2 \frac{(t-\mathrm{i} \Delta t)}{K} \mathrm{e}^{-(2 / K)(t-\mathrm{i} \Delta t)}+\frac{(t-\mathrm{i} \Delta t)^{2}}{K^{2}} \mathrm{e}^{-(2 / K)(t-\mathrm{i} \Delta t)}\right] \\
& +\sum_{i=0}^{m+1} C_{i 1} \sum_{i=0}^{m+1} C_{i 2} U(t-\mathrm{i} \Delta t)\left[2-4 \mathrm{e}^{-(1 / K)(t-\mathrm{i} \Delta t)}-2 \frac{(t-\mathrm{i} \Delta t)}{K} \mathrm{e}^{-(1 / K)(t-\mathrm{i} \Delta t)}\right] \\
& +\sum_{i=0}^{m+1} C_{i 1} \sum_{i=0}^{m+1} C_{i 2} U(t-\mathrm{i} \Delta t)\left[2 \mathrm{e}^{-(2 / K)(t-\mathrm{i} \Delta t)}+2 \frac{(t-\mathrm{i} \Delta t)}{K} \mathrm{e}^{-(2 / K)(t-\mathrm{i} \Delta t)}\right] \\
& +\sum_{i=0}^{m+1} C_{i 2} \sum_{i=0}^{m+1} C_{i 2} U(t-\mathrm{i} \Delta t)\left[1-2 \mathrm{e}^{-(1 / K)(t-\mathrm{i} \Delta t)}+\mathrm{e}^{-(2 / K)(t-\mathrm{i} \Delta t)}\right] \\
& +\frac{\sigma_{P_{1}^{\prime}}^{2}}{2 K}\left[1-\mathrm{e}^{-(2 / K) t}-\frac{2 t}{K} \mathrm{e}^{-(2 / K) t}-\frac{2 t^{2}}{K^{2}} \mathrm{e}^{-(2 / K) t}\right]+\frac{\sigma_{P_{2}^{\prime}}^{2}}{K}\left[1-\mathrm{e}^{-(2 / K) t}\right] \\
& E\left[Q_{n}^{2}(t)\right]=\sum_{w=1}^{n}\left\{\sum_{i=0}^{m+1} C_{i w} \sum_{i=0}^{m+1} C_{i w} U(t-\mathrm{i} \Delta t)\left[1-\sum_{a=0}^{n-w} \frac{2}{a ! K^{a}}(t-\mathrm{i} \Delta t)^{a} \mathrm{e}^{-(1 / K)(t-\mathrm{i} \Delta t)}\right]\right\} \\
& +\sum_{w=1}^{n}\left\{\sum _ { i = 0 } ^ { m + 1 } C _ { i w } \sum _ { i = 0 } ^ { m + 1 } C _ { i w } U ( t - \mathrm { i } \Delta t ) \left[\sum_{b=0}^{n-w} \frac{2^{b}}{b ! K^{b}}(t-\mathrm{i} \Delta t)^{b} \mathrm{e}^{-(2 / K)(t-\mathrm{i} \Delta t)}\right.\right. \\
& \left.\left.+\sum_{c=n-w+1}^{2(n-w)} R_{n w c}(n-w) \frac{(t-\mathrm{i} \Delta t)^{c}}{K^{c}} \mathrm{e}^{-(2 / K)(t-\mathrm{i} \Delta t)}\right]\right\} \\
& +\sum_{w=1}^{n-1} \sum_{i=0}^{m+1} C_{i w} \sum_{x=1}^{n-w} \sum_{i=0}^{m+1} C_{i(w+x)} U(t-\mathrm{i} \Delta t)\left\{2-2\left[\sum_{a=0}^{n-(w+x)} \frac{2}{a ! K^{a}}(t-\mathrm{i} \Delta t)^{a}\right.\right. \\
& \left.\left.+\sum_{b=(n-w-x)+1}^{n-w} \frac{1}{b ! K^{b}}(t-\mathrm{i} \Delta t)^{b}\right] \mathrm{e}^{-(1 / K)(t-\mathrm{i} \Delta t)}\right\} \\
& +\sum_{w=1}^{n-1} \sum_{i=0}^{m+1} C_{i w} \sum_{x=1}^{n-w} \sum_{i=0}^{m+1} C_{i(w+x)} U(t-\mathrm{i} \Delta t)\left\{\left[2+\sum_{d=1}^{2(n-w) u x} O_{n w x d} \frac{(t-\mathrm{i} \Delta t)^{d}}{K^{d}}\right] \mathrm{e}^{-(2 / K)(t-\mathrm{i} \Delta t)}\right\}
\end{aligned}
$$

$\mathrm{n}>1$ 
Table 1

The six selected typhoon events

\begin{tabular}{lll}
\hline Typhoon event & Time (year/month/date) & Note \\
\hline YANCY & $1990 / 8 / 17-1990 / 8 / 20$ & Calibration \\
POLLY & $1992 / 8 / 28-1992 / 8 / 31$ & Calibration \\
DOUG & $1994 / 8 / 7-1994 / 8 / 10$ & Calibration \\
FRED & $1994 / 8 / 19-1994 / 8 / 22$ & Calibration \\
SETH & $1994 / 10 / 9-1994 / 10 / 12$ & Calibration \\
HERB & $1996 / 7 / 30-1996 / 8 / 2$ & Verification \\
\hline
\end{tabular}

where $R_{n w c}$ and $O_{n w x d}$ are constants that change with $n$.

When $n=2, R_{212}=1, O_{2111}=2$; when $n=3$, $R_{313}=1 / 2, R_{314}=1 / 8, R_{322}=1, O_{3111}=4, O_{3112}=$ $3, O_{3113}=1, O_{3121}=2, O_{3122}=1$, and so on.

In reality, each subwatershed always has its own hydrologic and topographic characteristics. By applying the aforementioned method, one can obtain the first moment for subwatersheds with different $K$ parameters. For example, consider runoff from a watershed that can be divided into two subwatersheds. The first moment is

$$
\begin{aligned}
E\left[Q_{1}(t)\right]= & \sum_{i=0}^{m+1} C_{i 1} U(t-\mathrm{i} \Delta t)\left[1-\mathrm{e}^{-\left((t-\mathrm{i} \Delta t) / K_{1}\right)}\right] \\
E\left[Q_{2}(t)\right]= & \sum_{i=0}^{m+1} C_{i 1} U(t-\mathrm{i} \Delta t)[1 \\
& -\left(\frac{K_{1}}{K_{1}-K_{2}}\right) \mathrm{e}^{-\left((t-\mathrm{i} \Delta t) / K_{1}\right)} \\
& \left.+\left(\frac{K_{2}}{K_{2}-K_{1}}\right) \mathrm{e}^{-\left((t-\mathrm{i} \Delta t) / K_{2}\right)}\right] \\
& +\sum_{i=0}^{m+1} C_{i 2} U(t-\mathrm{i} \Delta t)\left[1-\mathrm{e}^{-\left((t-\mathrm{i} \Delta t) / K_{2}\right)}\right]
\end{aligned}
$$

for subwatersheds 1 and 2, respectively. The second moments for the first and second subwatersheds are

$$
\begin{aligned}
& E\left[Q_{1}^{2}(t)\right]=\sum_{i=0}^{m+1} C_{i 1} \sum_{i=0}^{m+1} C_{i 1} U(t-\mathrm{i} \Delta t) \\
& \times\left[1-2 \mathrm{e}^{-\left(1 / K_{1}\right)(t-\mathrm{i} \Delta t)}+\mathrm{e}^{-\left(2 / K_{1}\right)(t-\mathrm{i} \Delta t)}\right]+\frac{\sigma_{P_{1}^{\prime}}^{2}}{K_{1}}\left[1-\mathrm{e}^{-\left(2 / K_{1}\right) t}\right]
\end{aligned}
$$

$$
\begin{aligned}
& E\left[Q_{2}^{2}(t)\right]=\sum_{i=0}^{m+1} C_{i 1} \sum_{i=0}^{m+1} C_{i 1} U(t-\mathrm{i} \Delta t) \\
& \times\left[1-\frac{2 K_{1}}{K_{1}-K_{2}} \mathrm{e}^{-(1 / K)(t-\mathrm{i} \Delta t)}-\frac{2 K_{2}}{K_{2}-K_{1}} \mathrm{e}^{-\left(1 / K_{2}\right)(t-\mathrm{i} \Delta t)}\right] \\
& +\sum_{i=0}^{m+1} C_{i 1} \sum_{i=0}^{m+1} C_{i 1} U(t-\mathrm{i} \Delta t) \\
& \times\left[\frac{K_{1}^{2}}{\left(K_{1}-K_{2}\right)^{2}} \mathrm{e}^{-\left(2 / K_{1}\right)(t-\mathrm{i} \Delta t)}\right. \\
& +\frac{K_{2}^{2}}{\left(K_{1}-K_{2}\right)^{2}} \mathrm{e}^{-\left(2 / K_{2}\right)(t-\mathrm{i} \Delta t)} \\
& \left.-\frac{2 K_{1} K_{2}}{\left(K_{1}-K_{2}\right)^{2}} \mathrm{e}^{-\left(\left(1 / K_{1}\right)+\left(1 / K_{2}\right)\right)(t-\mathrm{i} \Delta t)}\right] \\
& +\sum_{i=0}^{m+1} C_{i 1} \sum_{i=0}^{m+1} C_{i 2} U(t-\mathrm{i} \Delta t) \\
& \times\left[2-\frac{2 K_{1}}{K_{1}-K_{2}} \mathrm{e}^{-\left(1 / K_{1}\right)(t-\mathrm{i} \Delta t)}\right. \\
& -\left(\frac{2 K_{2}}{K_{2}-K_{1}}+2\right) \mathrm{e}^{-\left(1 / K_{2}\right)(t-\mathrm{i} \Delta t)} \\
& -\left(\frac{2 K_{2}}{K_{1}-K_{2}}\right) \mathrm{e}^{-\left(2 / K_{2}\right)(t-\mathrm{i} \Delta t)} \\
& \left.+\frac{2 K_{1}}{K_{1}-K_{2}} \mathrm{e}^{-\left(\left(1 / K_{1}\right)+\left(1 / K_{2}\right)\right)(t-\mathrm{i} \Delta t)}\right] \\
& +\sum_{i=0}^{m+1} C_{i 2} \sum_{i=0}^{m+1} C_{i 2} U(t-\mathrm{i} \Delta t)\left[1-2 \mathrm{e}^{-\left(1 / K_{2}\right)(t-\mathrm{i} \Delta t)}\right. \\
& \left.+\mathrm{e}^{-\left(2 / K_{2}\right)(t-\mathrm{i} \Delta t)}\right] \\
& +\sigma_{P_{1}^{\prime}}^{2}\left[\frac{1}{K_{1}+K_{2}}-\frac{K_{1}}{\left(K_{1}-K_{2}\right)^{2}} \mathrm{e}^{-(2 / K) t}\right. \\
& -\frac{K_{2}}{\left(K_{1}-K_{2}\right)^{2}} \\
& \left.\times \mathrm{e}^{-\left(2 / K_{2}\right) t}+\frac{4 K_{1} K_{2}}{\left(K_{1}-K_{2}\right)^{2}\left(K_{1}+K_{2}\right)} \mathrm{e}^{-\left(\left(1 / K_{1}\right)+\left(1 / K_{2}\right)\right) t}\right] \\
& +\frac{\sigma_{P_{2}^{\prime}}^{2}}{K_{2}}\left[1-\mathrm{e}^{-\left(2 / K_{2}\right) t}\right]
\end{aligned}
$$

Substituting Eqs. (39) and (40) into the variance 


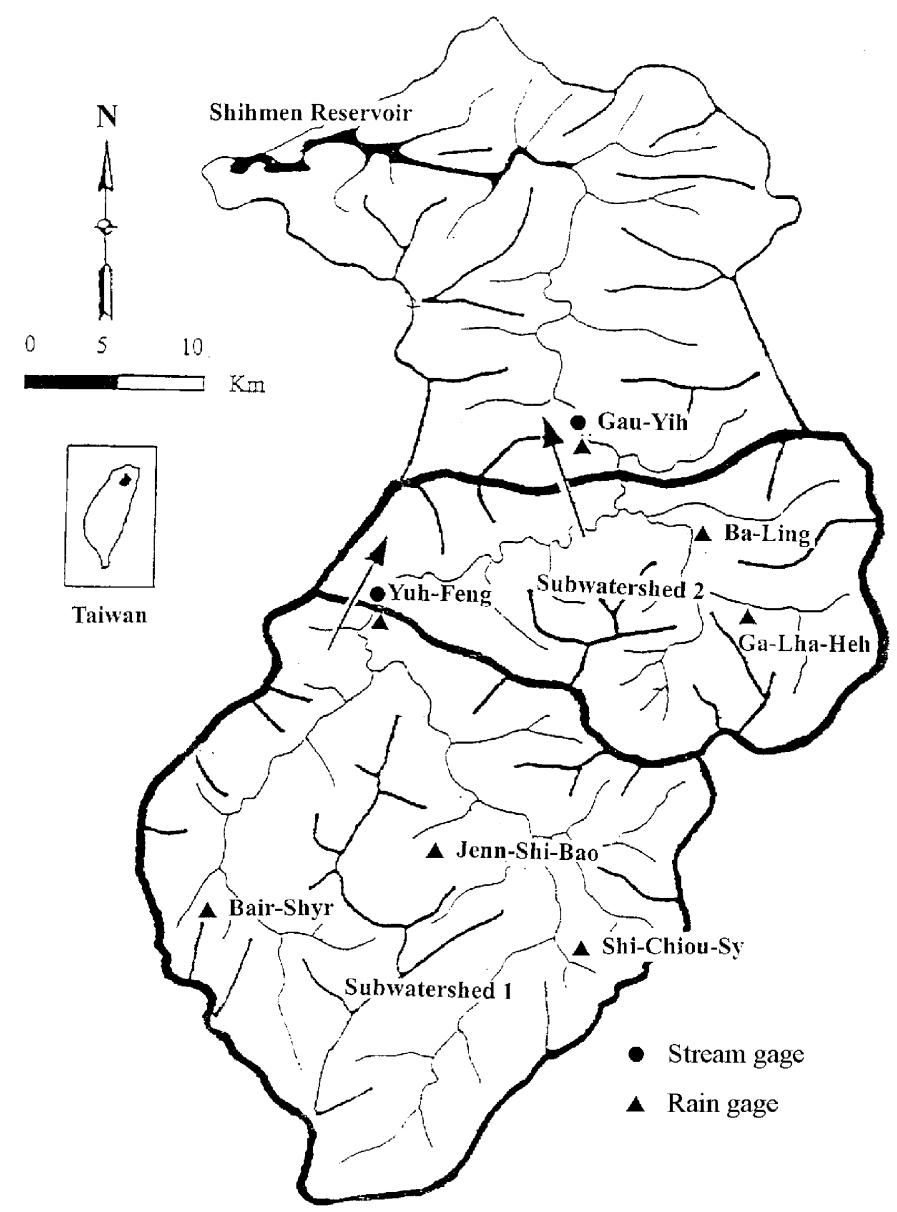

Fig. 1. Structure of two subwatersheds for the upstream watershed of Shihmen Reservoir in Taiwan.

equations below:

$\operatorname{Var}\left[Q_{1}\right]=E\left[Q_{1}^{2}\right]-\left\{E\left[Q_{1}\right]\right\}^{2}$

$\operatorname{Var}\left[Q_{2}\right]=E\left[Q_{2}^{2}\right]-\left\{E\left[Q_{2}\right]\right\}^{2}$

We can thus obtain the variation for the simulated runoff from the rainfall-runoff model.

\section{Application}

The stochastic series lumped model was applied to the Shihmen Reservoir Upstream watershed, a part of the Dahan River watershed. The Dahan River is the last tributary of the Tanshui River in Taiwan. Located in the foothills southwest of Taipei, the Shihmen
Reservoir was made by damming the Dahan River. The drainage pattern and hydrometric stations are displayed in Fig. 1. The watershed outline is formed by diastrophic ridges, which range in elevation from 135 to $3529 \mathrm{~m}$. It covers an area of $763.4 \mathrm{~km}^{2}$ at a mean elevation of $1417.2 \mathrm{~m}$. The length of the Dahan River is $94 \mathrm{~km}$ within the Shihmen Reservoir Upstream watershed. The soil types are primarily gravel sand loams, sand clay loams, and silt clay loams based upon Unified Soil Classification System (USCS). The land of the watershed is used primarily for fruit, tea, and rice crops, with part of the land is forest.

The mean annual rainfall is $2000 \mathrm{~mm}$ per year, with a recorded maximum of $2600 \mathrm{~mm}$. The rainy season generally begins in March and ends in August during 
Table 2

The calculated value of rainfall perturbation variance of each subwatershed

\begin{tabular}{lll}
\hline $\begin{array}{l}\text { Typhoon } \\
\text { event }\end{array}$ & $\begin{array}{l}\text { Subwatershed } 1 \\
\text { rainfall } \\
\text { perturbation } \\
\text { variance }\end{array}$ & $\begin{array}{l}\text { Subwatershed } 2 \\
\text { rainfall } \\
\text { perturbation } \\
\sigma_{P_{1}^{\prime}}^{2}(\mathrm{~mm} / \mathrm{h})^{2}\end{array}$ \\
$\begin{array}{lll}\text { variance } \\
\sigma_{P_{2}^{\prime}}^{2}(\mathrm{~mm} / \mathrm{h})^{2}\end{array}$ \\
\hline YANCY & 19.0 & 4.5 \\
POLLY & 12.4 & 8.9 \\
DOUG & 4.7 & 4.8 \\
FRED & 11.6 & 7.1 \\
SETH & 11.3 & 9.6 \\
\hline
\end{tabular}

which typhoons frequently occur. The intense rainy season, combined with the steep topography within the watershed, leads to large variations in runoff between high and low flows. Rainfall and runoff data for six typhoon rainfall events were processed by the Shihmen Reservoir Administration Bureau to produce rainfall excess hyetographs and direct runoff hydrographs. The six typhoon rainfall events are listed in Table 1.

Using the control area of the stream stations as a guide, the watershed was divided into two subwatersheds, interconnected in series according to their drainage patterns. The paths of the surface runoff are shown as arrows crossing the boundaries between the various units. The area upstream of the YuhFeng stream station represents subwatershed \# 1; the area between Gau-Yih and Yuh-Feng stream station represents subwatershed \# 2(Fig. 1).

The base flow is separated from the stream hydrograph directly by the methods of separation (Linsley et al., 1975) to derive the observed direct runoff hydrography. Uncertainty may exist in the base flow estimates using this approach. The quantity of base flow is small, compared with the quantity of runoff, and the effects of uncertainty may be neglected.

The $\Phi$-index method has been widely used to separate rainfall excess from losses due to infiltration into the ground water aquifer. It generally assumes that infiltration occurs at some constant rate throughout a storm. The volume of precipitation above the $\Phi$-index rate is considered as rainfall excess. To determine the $\Phi$-index for a given storm, the volume of direct runoff is determined from the observed hydrograph using the baseflow separation method described above. The volume of rainfall excess must equal the volume of direct runoff. Therefore, the value of $\Phi$ is set to meet this constraint (Linsley et al., 1975).

The mean values of the rainfall excess, $\bar{P}_{1}$ and $\bar{P}_{2}$, and the values of the variances $\sigma_{p_{1}^{\prime}}^{2}$ and $\sigma_{p^{2}}^{2}$ that are required in the stochastic model were estimated as follows. The measured rainfall at each time of data collection were averaged over the $1 \mathrm{~h}$ interval to determine the mean value for the time interval for the rain gauging station. Then, rainfall excess was obtained by the $\Phi$-index method from the hourly averaged rainfall. We, subsequently, applied the Thiessen polygon method to obtain the spatial average of rainfall excesses of all rain gauging stations in the subwatershed. Deviations of rainfall excess at all gauging stations from the average value provided the values of $\sigma_{P_{1}^{\prime}}^{2}, \sigma_{P_{2}^{\prime}}^{2}$ for each subwatershed (Table 2).

The simulation of runoff consisted of two steps: The first step was to calibrate, by an optimization method, the model parameters, which include the storage constant and the variance of the rainfall excess distribution. The second step was to verify the parameters for the model by predicting runoff due to the other recorded storm.

The time interval used in the calibration of the storage constant was $1 \mathrm{~h}$. The calibration proceeds with adjusting parameter $K$ to optimize the sum of square of the difference between observed and simulated direct runoff values in subwatershed \# 1 . The same procedure was used to calibrate the storage constant of subwatershed \# 2. The simulated runoff in subwatershed \# 1 with the optimized parameter gives an average coefficient of effect for the goodness-of-fit equal to 0.874 . The error in the estimated peak discharge was $0.38 \%$, and the error in the time to peak was less than $1 \mathrm{~h}$. For subwatershed \# 2, the average coefficient of effect is 0.899 , the error of peak discharge was $0.04 \%$, and the error of time-topeak is less than $2 \mathrm{~h}$. The results of calibration for each typhoon event are listed in Tables 3 and 4 and are represented by Figs. 2-5.

In theory, the coefficient of storage of the lump model of a subwatershed should be a constant. Results from our model calibration, however, show different coefficients of storage for each typhoon event for the same watershed (see Table 4). The mean storage 
coefficient is $8.44 \mathrm{~h}$ for subwatershed \# 1 and $4.26 \mathrm{~h}$ for subwatershed \# 2. The variances of the storage coefficients are $0.918 \mathrm{~h}^{2}$ and $1.908 \mathrm{~h}^{2}$ for the subwatersheds \#1 and \#2, respectively. The negative linear relationship between the storage constant and the simulated peak flow (Figs. 6 and 7) is also shown in our results. This relationship indicates that as the magnitude of the storage parameter increases, the magnitude of the simulated peak flow decreases. The model calibration results also show that the storage coefficient of subwatershed \# 1 is larger than subwatershed \# 2. This finding is consistent with the fact that the drainage area of subwatershed \# 2 is smaller than subwatershed \# 1 , and the length of main stream of subwatershed \# 2 is shorter than that of subwatershed \# 1 .

The results in Table 2 show that the magnitude of variance of rainfall perturbation also changes in response to typhoon events. The magnitude of the second order moment of simulated runoff increases when the magnitude of variance rainfall perturbation increases (see Fig. 8). A stochastic model allows us to find a value of variance for rainfall perturbation that yields a suitable range of simulated runoff. A suitable range of simulated runoff should be minimal, yet should comprise all available runoff data. The optimization was carried out manually in this case and the suitable ranges of simulated runoff are obtained. Calibrated values of variances of rainfall excess are listed in Table 5 and graphed in Figs. 9-12. Again, values in Table 5 are different from those values in Table 2, obtained from the measured data of rainfall using a statistical method. The average of these two tables gives an average variance value of subwatershed \# 1 is 11.8 , and the average variance value of subwatershed \# 2 is 7.0 .

To verify the model and the mean storage coefficient and variance of rainfall, rainfall and runoff data from the Herb typhoon event are utilized. Verification is accomplished by substituting the results of calibration into the stochastic lumped series rainfall-runoff model. The results of verification are listed in Table 6 and representative data are plotted in Figs. 13 and 14. The assessment of goodness-of-fit in subwatershed \# 1 gives a coefficient of effect of subwatershed \# 1 equal to 0.943 , the error of peak discharge is $3.9 \%$ and the error of time-to-peak is less than $2 \mathrm{~h}$. For subwatershed \#2, the average coefficient of effect is 


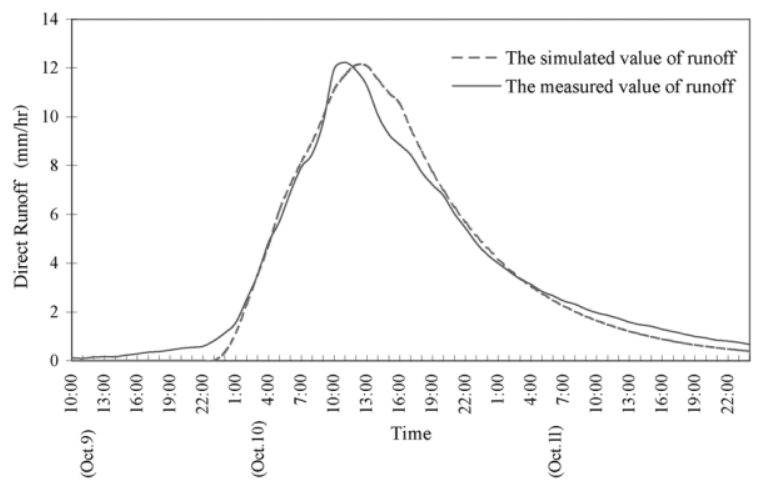

Fig. 2. The calibration of storage constant of subwatershed 1 for Seth typhoon event.

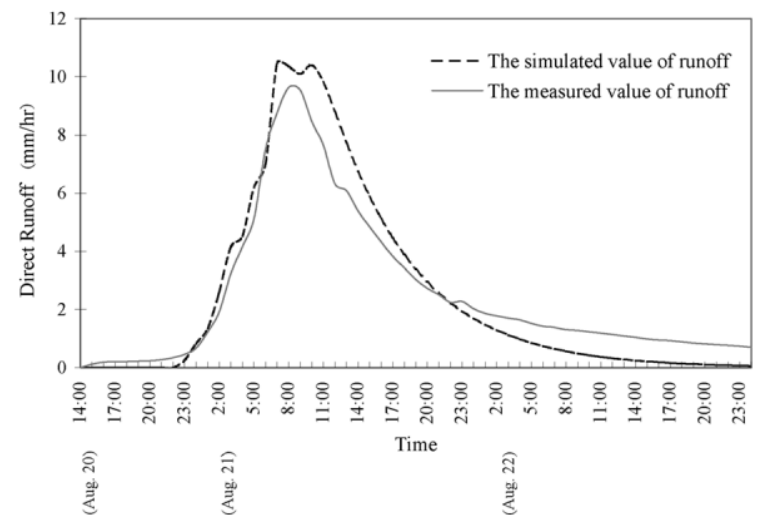

Fig. 3. The calibration of storage constant of subwatershed 1 for Fred typhoon event.

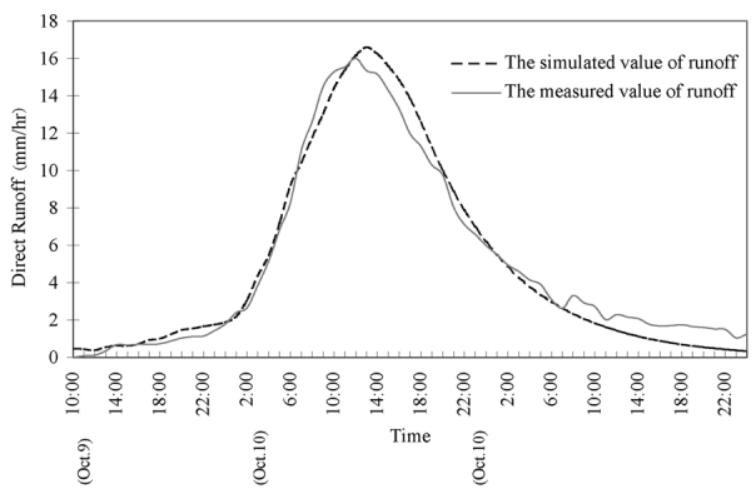

Fig. 4. The calibration of storage constant of subwatershed 2 for Seth typhoon event. 


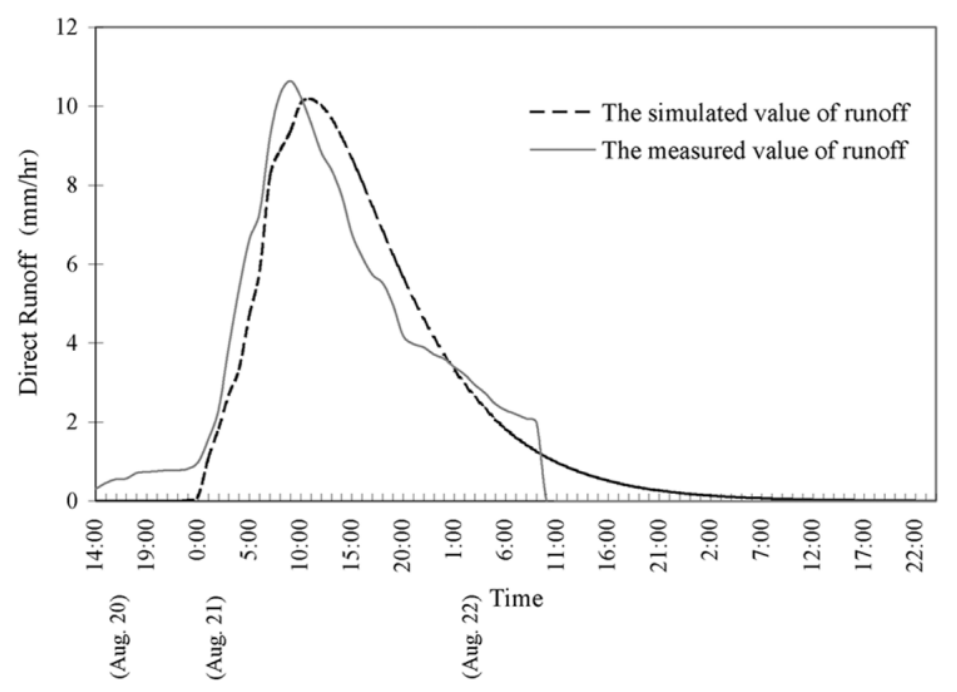

Fig. 5. The calibration of storage constant of subwatershed 2 for Fred typhoon event.

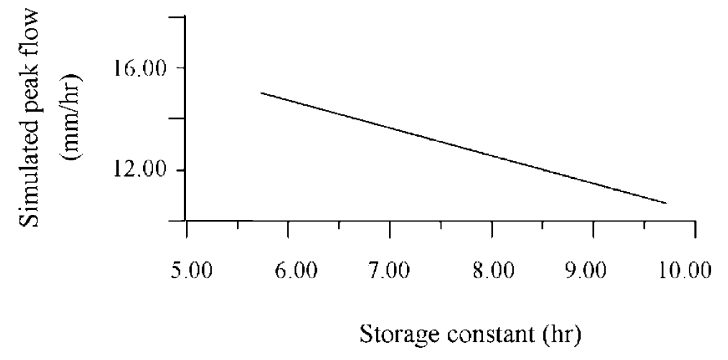

Fig. 6. The relational diagram of storage constant and peak flow of subwatershed 1 (Seth typhoon event).

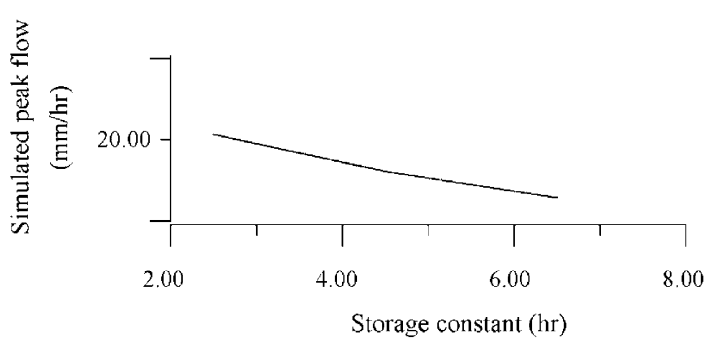

Fig. 7. The relational diagram of storage constant and peak flow of subwatershed 2 (Seth typhoon event).

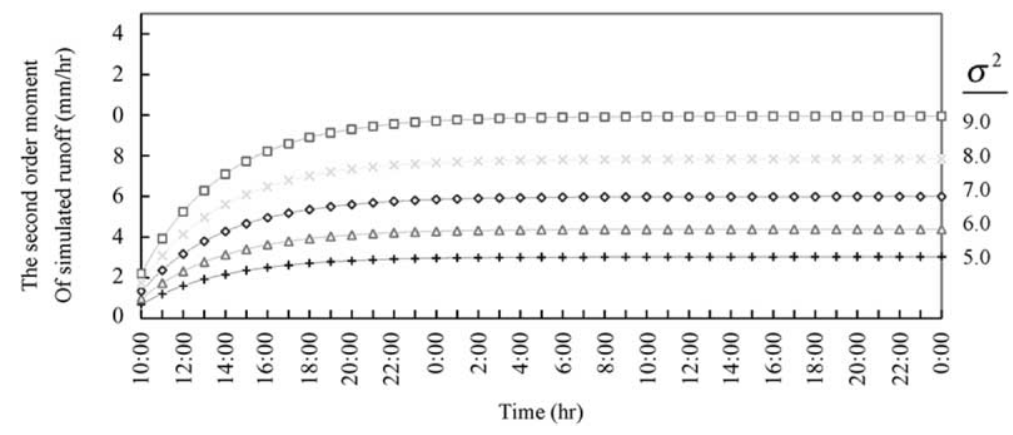

Fig. 8. The relational diagram of rainfall perturbation variance and the second order moment of runoff of subwatershed 1. 
Table 4

The calibrated result of storage constant of each subwatershed

\begin{tabular}{lll}
\hline $\begin{array}{l}\text { Typhoon } \\
\text { event }\end{array}$ & $\begin{array}{l}\text { Subwatershed 1 } \\
\text { storage constant } \\
K_{1}(\mathrm{~h})\end{array}$ & $\begin{array}{l}\text { Subwatershed 2 } \\
\text { storage constant } \\
K_{2}(\mathrm{~h})\end{array}$ \\
\hline YANCY & 8.6 & 4.3 \\
POLLY & 8.9 & 5.5 \\
DOUG & 7.7 & 5.7 \\
FRED & 7.3 & 3.3 \\
SETH & 9.7 & 2.5 \\
\hline
\end{tabular}

0.914 , the error of peak discharge is $8.7 \%$, and the error of time-to-peak is less than $1 \mathrm{~h}$. It can be seen in Figs. 13 and 14 that part of the observed runoff is not within the standard deviation of the fluctuant range of simulated runoff, but the peak is within the range. Therefore, the model is suitable for simulating the runoff of the upstream watershed of Shihmen Reservoir in Taiwan.

\section{Summary}

A stochastic rainfall-runoff model was constructed based on the concept of a series of lumped systems and the theory of SDE. The rainfall excess input to the model is treated as a stochastic process with a unitstep function.

A stochastic differential equation described the relationship between the mean rainfall excess and the mean direct runoff from a series of subwatersheds was formulated. A differential equation that relates the second moment of the rainfall excess to that of

Table 5

The optimalized value of rainfall perturbation variance of each subwatershed

\begin{tabular}{lll}
\hline $\begin{array}{l}\text { Typhoon } \\
\text { event }\end{array}$ & $\begin{array}{l}\text { Subwatershed 1 } \\
\text { rainfall } \\
\text { perturbation } \\
\text { variance } \sigma_{P_{1}^{\prime}}^{2} \\
(\mathrm{~mm} / \mathrm{h})^{2}\end{array}$ & $\begin{array}{l}\text { Subwatershed 2 } \\
\text { rainfall } \\
\text { perturbation } \\
\text { variance } \sigma_{P_{2}^{\prime}}^{2} \\
(\mathrm{~mm} / \mathrm{h})^{2}\end{array}$ \\
\hline YANCY & 7.3 & 4.7 \\
POLLY & 9.5 & 5.2 \\
DOUG & 8.5 & 5.7 \\
FRED & 6.1 & 3.3 \\
SETH & 5.0 & 3.2 \\
\hline
\end{tabular}

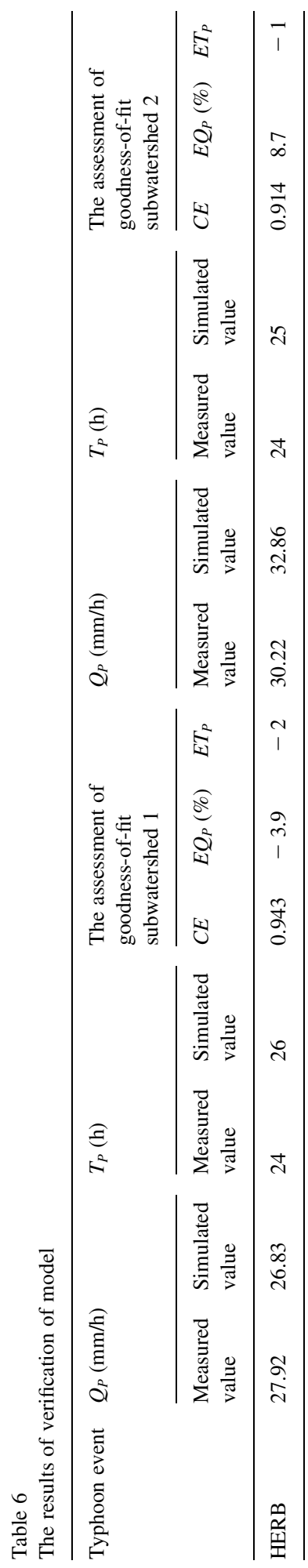




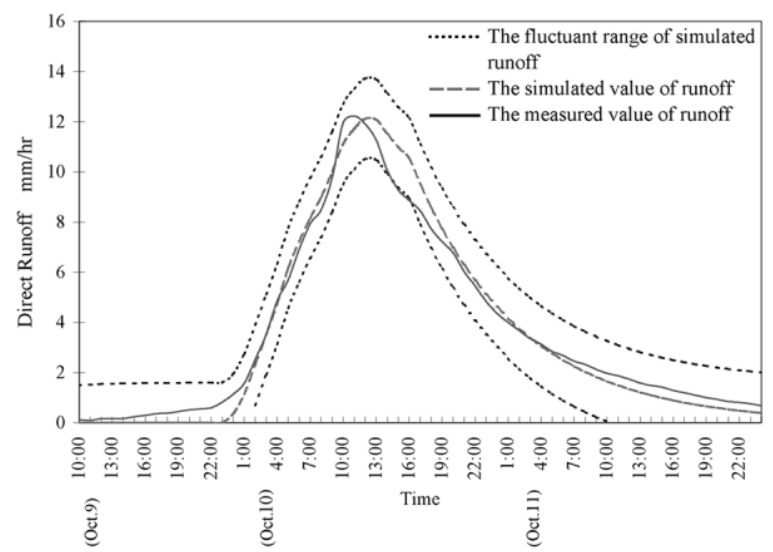

Fig. 9. The calibration of rainfall perturbation variance of subwatershed 1 for Seth typhoon event.

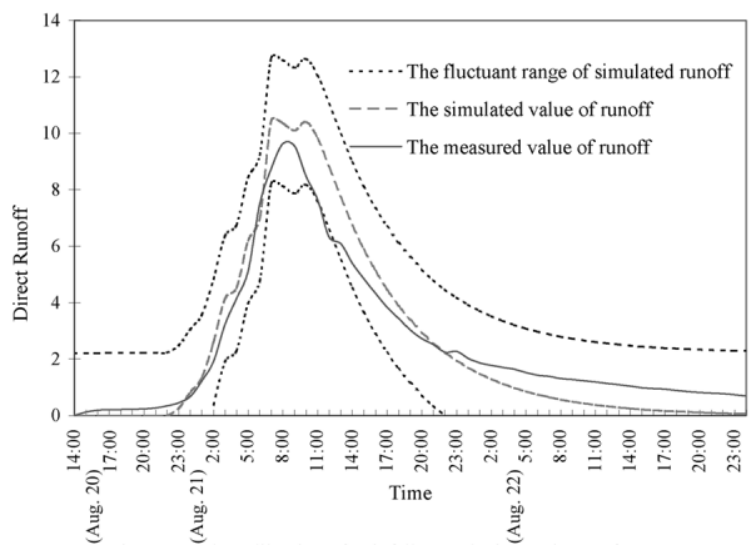

Fig. 10. The calibration of rainfall perturbation variance of subwatershed 1 for Fred typhoon event.

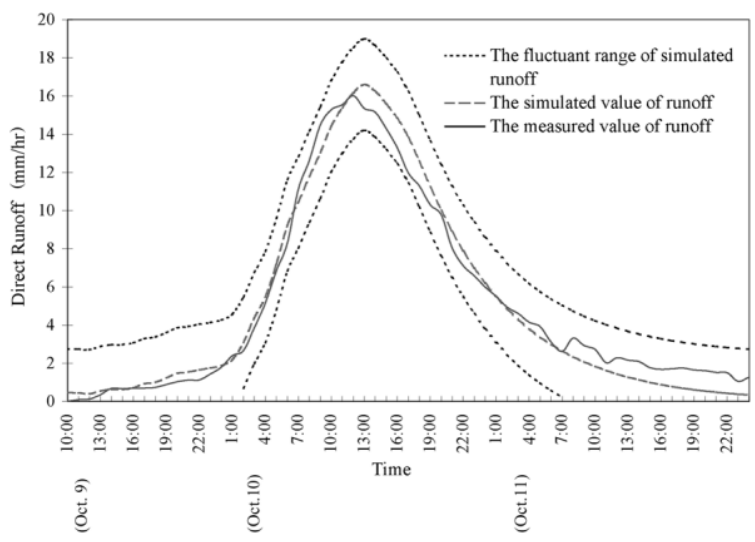

Fig. 11. The calibration of rainfall perturbation variance of subwatershed 2 for Seth typhoon event. 


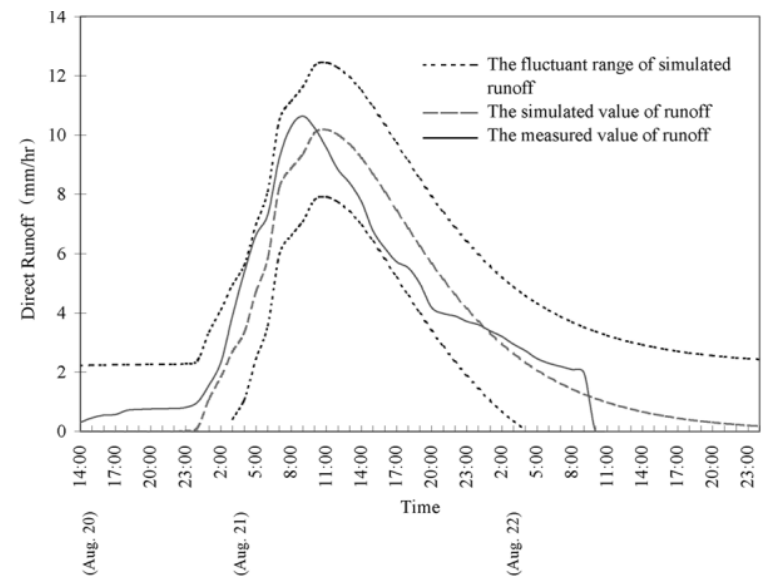

Fig. 12. The calibration of rainfall perturbation variance of subwatershed 2 for Fred typhoon event.

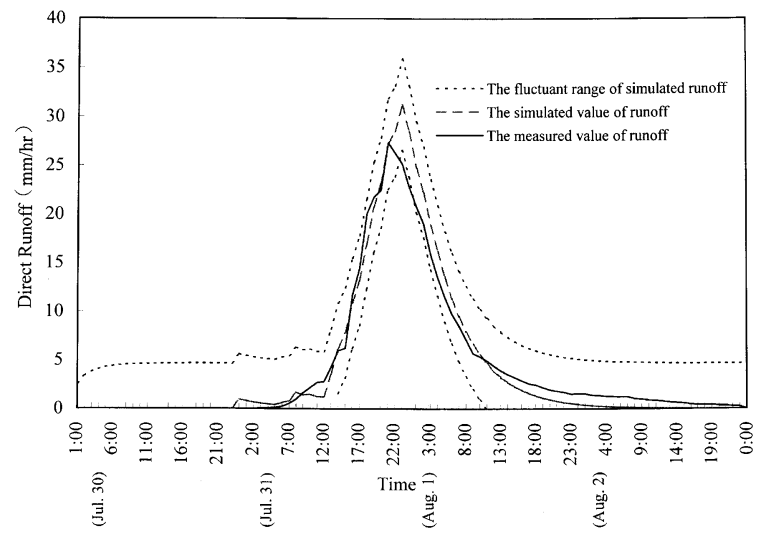

Fig. 13. The verification of rainfall perturbation variance and storage constant of subwatershed 1 for Herb typhoon event.

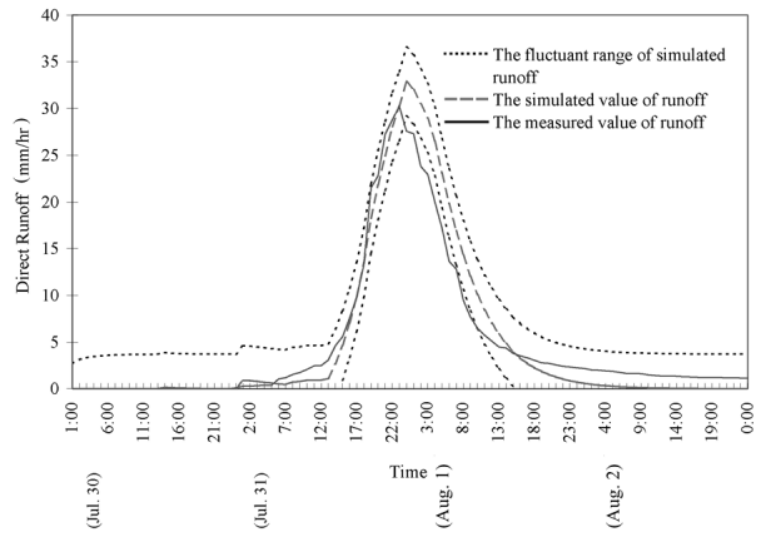

Fig. 14. The verification of rainfall perturbation variance and storage constant of subwatershed 2 for Herb typhoon event. 
direct runoff from the subwatersheds was also developed. A Laplace transform technique was then used to derive the solution of the SDE. This approach allows us to calculate the expected value and variance of direct runoff by directly solving the first- and second-order moment equations without using brute-force Monte Carlo simulations. The mean and variance of direct runoff is essential for the purpose of water resource management of a watershed.

Subsequently, the stochastic model was applied to the Shihmen Reservoir upstream watershed. Using topography and the control area of stream flow stations as a guide, the area of the watershed was divided into two subwatersheds. The division of the watershed reduces effects in simulation due to spatial variability. The model was calibrated for several storm events to obtain optimal model parameters. The parameters were then used to predict other storm event. The results are satisfactory.

\section{Acknowledgements}

Support for this study was provided by the National Science Council of Taiwan under grant NSC 88-2313B-002-099. The authors are also grateful for the contributions of Dr Chen-Wuing Liu, Dr Chun-Nan Lin, Dr Gwo-Hsing Yu, and Dr Miau-Bin Su.

\section{References}

Bodo, B.A., Unny, T.E., 1987. On the ouputs of the stochasticized
Nash-Dooge linear reservoir cascade. In: Macneill, I.B., Umphrey, G.J. (Eds.). Stochastic Hydrology. , pp. 131-147.

Heaviside, O., 1971. Electromagnetic Theory: Including an Account of Heaviside's Unpublished Notes for a Fourth Volume. 3rd ed.. Chelsea Publish Company, New York.

Hjelmfelt, A., Bruwell, R., 1984. Spatial variability of runoff. J. Irrig. Drain. Engng 110 (1), 46-54.

Hromodka II, T.V., Whitley, R.J., 1994. A stochastic integral equation analog of rainfall-runoff processes for evaluating modeling uncertainty. Stoch. Hydrol. Hydraul. 8, 259-268.

Klemes, V., 1974. Probability distribution of outflow from a linear reservoir. J. Hydrol. 21, 305-314.

Linsley, R.K., Kohler, M.A., Paulhus, J.L.H., 1975. Hydrology for Engineers. 2nd ed.. McGraw-Hill, New York.

Moran, P.A.P., 1971. Dams in series with a continuous release. J. Appl. Prob. 4, 380-388.

Quimpo, R.G., 1971. Structural relation between parametric and stochastic hydrology. Mathematical models in hydrology, vol. 1, Int. Assoc. Hydrol. Sci. Publ. 100, 151-157.

Quimpo, R.G., 1973. Link between stochastic and parametric hydrology. J. Hydraul. Div. Am. Soc. Civil Engng 99, 461-470.

Sarino, S.E., Serrano, 1990. Development of the instantaneous unit hydrograph using stochastic differential equations. Stoch. Hydrol. Hydraul. 4, 151-160.

Sherman, L.K., 1932. Stream-flow from rainfall by the Unit Graph Method. Engng News Rec. 108, 501-505.

Soong, T.T., 1973. Random Differential Equations in Science and Engineering. Academic Press, New York.

Unny, T.E., 1984. Numerical integration of stochastic differential equation in catchment modeling. Water Resour. Res. 20 (3), 360-368.

Unny, T.E., Karmeshu, 1984. Stochastic nature of outputs from conceptual reservoir model cascades. J. Hydrol. 33, 161-180.

Wang, G.-T., Chen, S., 1996. Alinear spatiality distributed model for a surface rainfall-runoff system. J. Hydrol. 185, 183-198.

Weiss, G., 1973. Shot noise models for synthetic generation of multisite daily streamflow data. Water Resources Projects with Inadequate Data, Int. Assoc. Hydrol. Sci. Publ. 108, 457-467. 